\title{
Upscaling of LATP synthesis: Stoichiometric screening of phase purity and microstructure to ionic conductivity maps
}

\author{
Nikolas Schiffmann ${ }^{1} \cdot$ Ethel C. Bucharsky ${ }^{1} \cdot$ Karl G. Schell $^{1} \cdot$ Charlotte A. Fritsch $^{2} \cdot$ Michael Knapp $^{2}$. \\ Michael J. Hoffmann ${ }^{1}$
}

Received: 29 October 2020 / Revised: 14 January 2021 / Accepted: 7 February 2021 / Published online: 3 March 2021

(C) The Author(s) 2021, corrected publication 2021

\begin{abstract}
Lithium aluminum titanium phosphate (LATP) is known to have a high Li-ion conductivity and is therefore a potential candidate as a solid electrolyte. Via sol-gel route, it is already possible to prepare the material at laboratory scale in high purity and with a maximum Li-ion conductivity in the order of $1 \cdot 10^{-3} \mathrm{~s} / \mathrm{cm}$ at room temperature. However, for potential use in a commercial, battery-cell upscaling of the synthesis is required. As a first step towards this goal, we investigated whether the sol-gel route is tolerant against possible deviations in the concentration of the precursors. In order to establish a possible process window for sintering, the temperature interval from $800{ }^{\circ} \mathrm{C}$ to $1100{ }^{\circ} \mathrm{C}$ and holding times of 10 to $480 \mathrm{~min}$ were evaluated. The resulting phase compositions and crystal structures were examined by X-ray diffraction. Impedance spectroscopy was performed to determine the electrical properties. The microstructure of sintered pellets was analyzed by scanning electron microscopy and correlated to both density and ionic conductivity. It is shown that the initial concentration of the precursors strongly influences the formation of secondary phases like $\mathrm{AlPO}_{4}$ and $\mathrm{LiTiOPO}_{4}$, which in turn have an influence on ionic conductivity, densification behavior, and microstructure evolution.
\end{abstract}

Keywords LATP $\cdot$ Sol-gel route $\cdot$ Solid state electrolyte $\cdot$ Synthesis upscaling $\cdot$ Ionic conductivities

\section{Introduction}

Currently, many solid-state electrolytes are being investigated as substitutes for liquid electrolytes to improve energy storage safety and energy density in next generation batteries. Challenges such as the thermodynamic instability against the Li-anode have hampered the implementation of solid-state electrolytes in cells in the past. Nevertheless, targeted investigations of the failure mechanisms and the use of suitable protective intermediate layers will help to enable an efficient use of their advantages in future cell designs [1-4]. Ceramics derived from the NASICON (sodium super ionic conductor)-

Nikolas Schiffmann

nikolas.schiffmann@kit.edu

1 Institute for Applied Materials - Ceramic Materials and Technologies, Karlsruhe Institute of Technology (KIT), Haid-und-Neu-Str. 7, 76131 Karlsruhe, Germany

2 Institute for Applied Materials - Energy Storage Systems, Karlsruhe Institute of Technology (KIT), Hermann-von-Helmholtz-Platz 1, 76344 Eggenstein-Leopoldshafen, Germany type structure $\mathrm{LiTi}_{2}\left(\mathrm{PO}_{4}\right)_{3}$ have emerged as particularly promising solid electrolyte candidates due to their high ionic conductivity, low cost, and stability on air and in water. Their crystallographic structure can be described as two $\mathrm{TiO}_{6}$ octahedrons connected at the corners by three $\mathrm{PO}_{4}$ tetrahedra forming the characteristic lantern shaped structure as seen in Fig. 1. The Li-ions are located in vacancies that exist along the $\mathrm{c}$-axis above and below each lantern, called $\mathrm{M}_{1}$ Position $(6 b)$. A partial substitution of the $\mathrm{Ti}^{4+}$ cation by trivalent cations, such as $\mathrm{Al}^{3+}, \mathrm{Fe}^{3+}$, or $\mathrm{Sc}^{3+}$, generates a deficiency in positive charge, which is compensated by the addition of $\mathrm{Li}^{+}[5]$. This promotes the occupancy of additional $\mathrm{M}_{2}$ sites (18e) in between the $\mathrm{M}_{1}$ sites, forming a three-dimensional conduction network in which the ions can move [6]. Through external influence, e.g., temperature, the $\mathrm{Li}^{+}$ions are deflected from their central position of the respective crystallographic site to so called $\mathrm{M}_{1 / 2}$ sites, which are arranged in a hexagonal ring around the $\mathrm{M}_{1}$ position. According to literature, the occupation of these $M_{1 / 2}$ sites shows a considerable influence on lithium mobility $[7,8]$. The ionic conductivity is particularly high for the composition $\mathrm{Li}_{1.3} \mathrm{Al}_{0.3} \mathrm{Ti}_{1.7}\left(\mathrm{PO}_{4}\right)_{3}$ for which several studies have reported values up to $10^{-3} \mathrm{~s} / \mathrm{cm}[5,9-12]$. 
Fig. 1 Schematic structure of the NASICON-type crystal structure. The Roman numerals indicate the valence of the atoms involved. Red spheres represent the oxygen atoms, yellow spheres phosphor, gray spheres lithium, and purple spheres titanium. For better clarity, individual oxygen atoms have been omitted as well as the valence of all oxygen atoms (-II). A movement of the $\mathrm{Li}^{+}$ions is possible through the cross-linked vacancies $\mathrm{M}_{1}$ and $\mathrm{M}_{2}[6,13]$

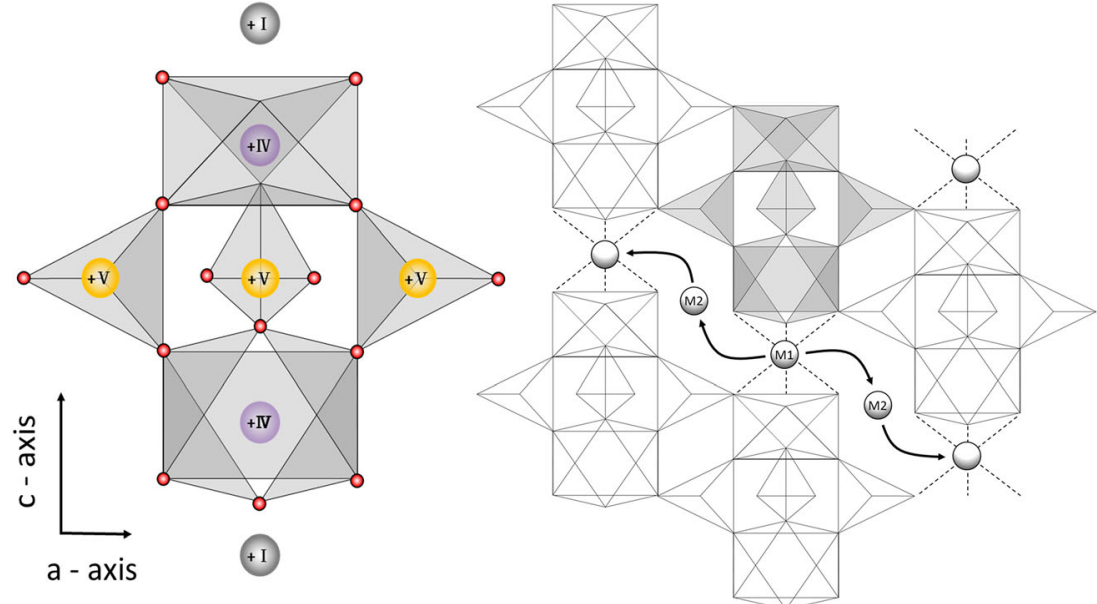

$\mathrm{Li}_{1.3} \mathrm{Al}_{0.3} \mathrm{Ti}_{1.7}\left(\mathrm{PO}_{4}\right)_{3}$ ceramics have been successfully synthesized by different routes, such as calcination of stoichiometric mixtures of oxide precursors [14], by glass crystallization [11], or by sol-gel [12, 15]. However, these studies focus on an output limited to a laboratory scale. To render ceramic electrolytes usable in next generation batteries, processing routes need to be identified to upscale production. The solgel route is already successfully used on a large scale in industry for other materials and therefore provides a good basis for LATP synthesis [16]. In order to ensure quality maintenance and reproducibility, the crucial processing parameters have to be identified. As a first step towards an upscaling of LATP production via the sol-gel route, we investigated the influence of possible deviations in the concentration of the precursors. This applies especially to phosphoric acid, difficult to specify due to its hygroscopy. In case the precursors are not exactly stoichiometric, this can easily lead to secondphase formation. In particular, for LATP, such second phases have a great influence on densification and ionic conductivity. In the work of Hupfer et al. [17], it is described how the second phases $\mathrm{AlPO}_{4}$ and $\mathrm{LiTiOPO}_{4}$ can impact the properties of LATP.

In the following, we study the LATP synthesis by varying concentration of the reactants, dwell time, and sintering temperatures and relate them to microstructure, phase composition, and ionic conductivity.

\section{Materials and methods}

\section{Synthesis of LATP}

The LATP powders were prepared following a modified solgel synthesis route described by Bucharsky et al. [12]. The starting materials for this method are lithium acetate $\mathrm{Li}\left(\mathrm{C}_{2} \mathrm{H}_{3} \mathrm{O}_{2}\right) \cdot 2 \mathrm{H}_{2} \mathrm{O}$ (purity $\geq 99 \%$, Alfa Aesar GmbH \& Co $\mathrm{KG}$, Germany), aluminum nitrate $\mathrm{Al}\left(\mathrm{NO}_{3}\right)_{3} \cdot 9 \mathrm{H}_{2} \mathrm{O}$ (purity $\geq$
98.5\%, Merck KGaA, Germany), titanium-isopropoxide $\mathrm{Ti}\left[\mathrm{OCH}\left(\mathrm{CH}_{3}\right)_{2}\right]_{4}$ (purity $\geq 98 \%$, Merck KGaA, Germany), and phosphoric acid $\mathrm{H}_{3} \mathrm{PO}_{4}$ (purity $\geq 85 \%$, Merck KGaA, Germany). First, lithium acetate and aluminum nitrate were completely dissolved in an appropriate amount of water. Subsequently, the titanium-isopropoxide was added dropwise. The anion source, phosphoric acid, was then added slowly to form a white gel. The heat treatment was performed in two steps, the first at $400{ }^{\circ} \mathrm{C}$ for $6 \mathrm{~h}$ to achieve the precursor formation and eliminate reaction gases, the second one at $900{ }^{\circ} \mathrm{C}$ for $8 \mathrm{~h}$ to complete the reaction to crystalline LATP. One sol-gel batch was prepared with all precursors in stoichiometric quantities. To test whether the sol-gel route is tolerant against possible deviations in the concentration of the precursors, two more sol-gel batches were made with either an excess, "LATPex", or a deficiency, "LATPdef", of 7.5 wt $\%$ phosphoric acid compared to the stoichiometric composition "LATPst".

\section{Sample preparation}

The powders obtained after the two-step heat treatment were further processed in a planetary mill to reduce particle size, which ensures a high sinterability. The milling was performed in heptane for $16 \mathrm{~h}$ in polyurethane jars employing $\mathrm{Si}_{3} \mathrm{~N}_{4}$ milling balls. The milled powders were subsequently heated to $650{ }^{\circ} \mathrm{C}$ to burn out any organic residue. The particle size development during the milling process was monitored employing the Brunauer-Emmett-Teller (BET) method. There, the specific surface, $\mathrm{O}_{\text {tot, }}$ is determined by nitrogen adsorption. The particle size is then calculated as an equivalent particle diameter, $\mathrm{d}$, under the assumption of spherical particles and the theoretical density of LATP $\left(2.93 \mathrm{~g} / \mathrm{cm}^{3}\right)$ according to

$\mathrm{d}=\frac{6}{O_{\text {tot }} \cdot \rho_{\text {theo }}}$ 
The change of the specific surface of the LATP powder over the course of the milling process is shown in Fig. 2a. A reduction in particle size from initially around $2.1 \mu \mathrm{m}$ to approximately $45 \mathrm{~nm}$ after milling is achieved. The size magnitude of the LATP particles was confirmed by scanning electron microscopy as depicted in Fig. 2b. Finally, pellets were made by uniaxial and cold isostatic pressing with $400 \mathrm{MPa}$. The samples were sintered at temperatures ranging from $800{ }^{\circ} \mathrm{C}$ to $1100{ }^{\circ} \mathrm{C}$ with a heating rate of $5{ }^{\circ} \mathrm{C} / \mathrm{min}$. The isothermal sintering time was varied between $10 \mathrm{~min}$ and $480 \mathrm{~min}$. The density of the samples was determined by Archimedes' method.

\section{Phase assemblage}

The crystal structure of all powders and pellets was examined by X-ray diffraction (D8 ADVANCE, Bruker, Germany). For the measurement, a $2 \theta$ angle range from $10^{\circ}$ to $65^{\circ}$ in increments of $0.01^{\circ}$ using an integration time of $0.2 \mathrm{~s}$ per step was employed $(\lambda=1.54187 \AA)$. The obtained patterns were compared with references from the PDF-2 database ("International Center for Diffraction Data" (ICDD)) for identification. Diffraction patterns for Rietveld analysis were recorded with an STOE Stadi P powder diffractometer with Mo-K $\alpha_{1}$ radiation $(\lambda=0.70932 \AA)$ in transmission geometry and a single Mythen- 1 detector from $2 \theta=4^{\circ}$ to $60^{\circ}$ with a step width of $0.3^{\circ}$ and an integration time of $40 \mathrm{~s}$ per step. The instrumental resolution function was determined with a $\mathrm{LaB}_{6}$ reference [18]. The Rietveld refinement was performed using the FullProf software package.

\section{Microstructural characterization}

Sintered pellets were embedded in epoxy resin and the first layer was ground off to obtain a material not affected by surface sintering effects. The samples were then polished with diamond slurry before taking images by SEM (Nova NanoSEM 450, FEI).

\section{Electrical measurements}

For the ionic conductivity measurements, the samples had a cylindrical shape and were polished to surface parallel and a height of about $2 \mathrm{~mm}$, the diameter was about $8 \mathrm{~mm}$. The exact geometry for each individual sample was determined by averaging three measured values obtained by a caliper. A conductive layer of gold, on both sides, was sputtered for $120 \mathrm{~s}$ with a current of $25 \mathrm{~mA}$ under an argon atmosphere (Quorum Technologies Ltd, Q150T ES, UK). The impedance analysis was performed at room temperature in the potentiostatic mode at open circuit potential over the frequency range from $0.1 \mathrm{~Hz}$ to $1 \mathrm{MHz}$ with an $\mathrm{AC}$ amplitude of $50 \mathrm{mV}$ using a frequency response analyzer (AMETEK $\mathrm{GmbH}$, VersaSTAT 4, USA). The impedance data were analyzed using the Zview software (Scribner Associates Inc., USA).

The parts of the semicircles seen in the Nyquist plot, as shown in the inset of Fig. 3, were assigned to grain boundary conductivity. It can be considered as the total conductivity sigma for LATP, since it is orders of magnitude lower than the bulk conductivity and therefore limiting. The ionic conductivity can then be determined for each measured frequency from the real and imaginary parts of the impedance and the geometry of the sample according to Eq. 2:

$\sigma=\frac{Z^{\prime}}{Z^{\prime 2}+Z^{\prime \prime 2}} * \frac{l}{A}$,

where $A$ is the cross-sectional area of the sample and $l$ is the height. We then take the total conductivity to be the value of the plateau in the plot of conductivity over frequency, as illustrated in Fig. 3.

\section{Results and discussion}

The XRD patterns for calcined LATP powders derived from all sol-gel batches are depicted on the left side of Fig. 4. Apparently, the calcined $\mathrm{Li}_{1.3} \mathrm{Al}_{0.3} \mathrm{Ti}_{1.7}\left(\mathrm{PO}_{4}\right)_{3}$ powders crystalize in the trigonal NASICON-type structure (R-3c, space
Fig. 2 (a) Specific surface of the LATP powder determined by BET analysis with calculated equivalent particle diameters. (b) SEM image of LATP powder after milling
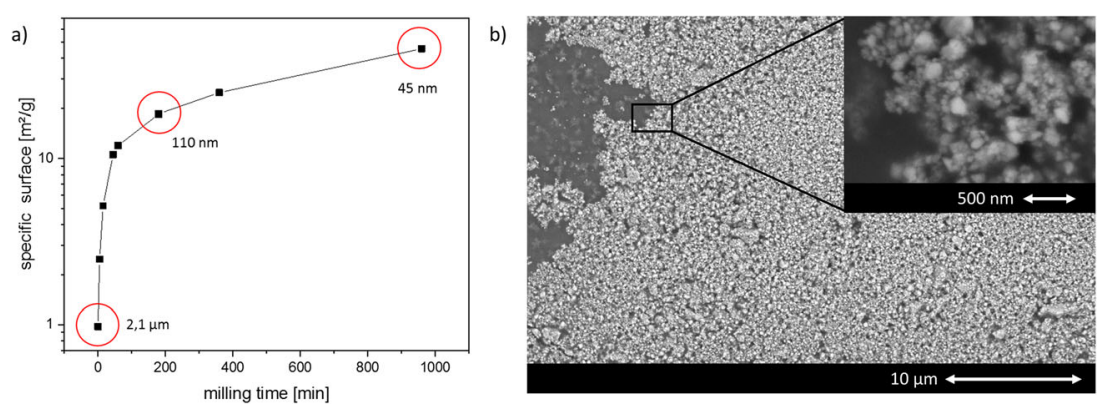


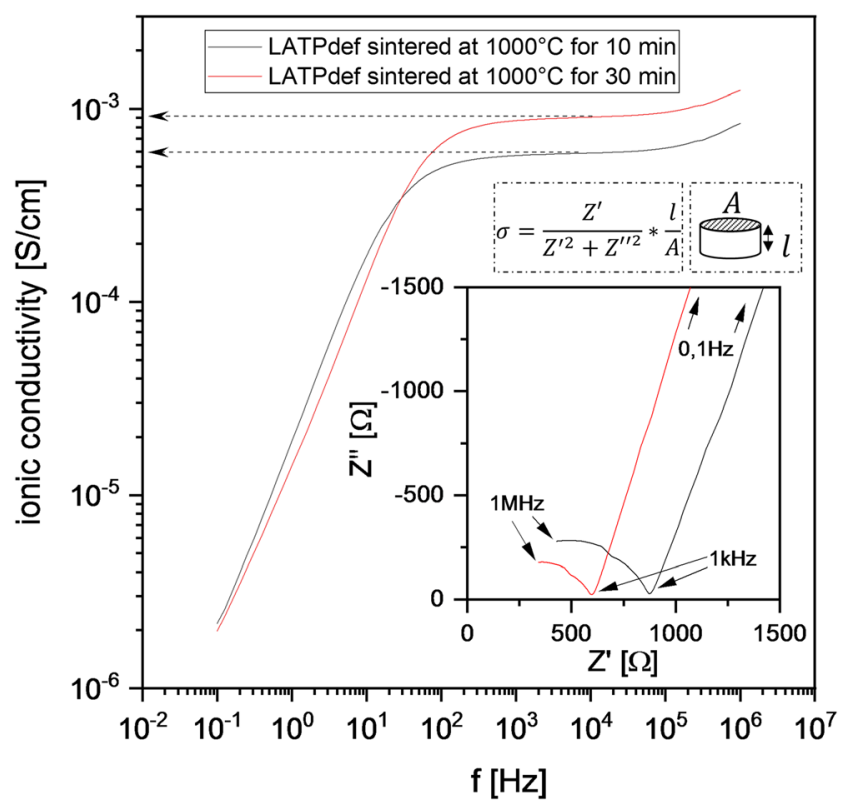

Fig. 3 Exemplary ionic conductivity of LATP samples (LATPdef sintered at $1000{ }^{\circ} \mathrm{C}$ ) calculated from real and imaginary part of the impedance (shown as Nyquist-plot in the inset) and the sample geometry. The dotted arrows indicate the identified ionic conductivity at the plateaus.

group No. 167) from the PDF-2-database (ICDD). In the enlarged XRD patterns on the right side of Fig. 4, the second phases are marked which were formed in LATPex and LATPdef. An excess of $7.5 \mathrm{wt} \% \mathrm{H}_{3} \mathrm{PO}_{4}$ leads to the formation of $4.7 \mathrm{wt} \% \mathrm{AlPO}_{4}$ and a deficit of $7.5 \mathrm{wt} \% \mathrm{H}_{3} \mathrm{PO}_{4}$ to $5.6 \mathrm{wt} \%$ $\mathrm{LiTiOPO}_{4}$ as an impurity, as calculated with Rietveld refinement.

Further, crystallographic information extracted from the refinement is listed in Table 1. The graphs of the refinements are depicted in the Supporting Information (Figure S11-S16). The phase-pure calcined LATPst sample shows the least amount of microstructural strain in the powder analysis. A comparably larger volume of the unit cell is observed for calcined LATPex. The cell volume of calcined LATPdef is comparable to the cell volume of calcined LATPst with a slightly increased microstrain. No size broadening could be detected.

Small changes in the synthesis route cause the formation of second phases and influence the unit cell size. We investigated how these differences affect the sintering behavior, microstructure evolution, and the resulting ionic conductivity.

Therefore, the calcined powders were treated in a planetary ball mill to decrease the particle size and consequently increase the sinterability. All pressed samples had a green density of approximately $62 \%$ relative density. The sintering behavior was analyzed for temperatures from $800^{\circ} \mathrm{C}$ up to 1100 ${ }^{\circ} \mathrm{C}$ in steps of $100{ }^{\circ} \mathrm{C}$. For each temperature isothermal durations of 10, 30,60, and 480 min were applied. The results for all LATP batches are shown in a density map given in Fig. 5. The exact values of relative density for the different sintering temperatures and holding times are listed in Table $2-4$. The relative density of stoichiometric samples sintered at $800{ }^{\circ} \mathrm{C}$ increased from $72 \%$ for 10 min soaking time up to $92 \%$ for $480 \mathrm{~min}$. A significant densification to $>96 \%$ relative density can be observed for short soaking times at $900{ }^{\circ} \mathrm{C}$, whereas longer isothermal sintering and higher sintering temperatures result in less dense samples. The pellets made from LATPex powder indicate the highest density of maximum $94 \%$ relative density for short sintering times at $900{ }^{\circ} \mathrm{C}$ or at longer isothermal sintering at $800{ }^{\circ} \mathrm{C}$. A completely different behavior emerges from samples produced from the LATPdef powder: significant densification requires sintering temperatures $\geq 1000{ }^{\circ} \mathrm{C}$ where the density reaches a value of $85 \%$ after $10 \mathrm{~min}$ and its maximum of almost $98 \%$ for a holding time of 480 minutes. Further increase in temperature to $1100{ }^{\circ} \mathrm{C}$ does not lead to higher densities.
Fig. 4 XRD patterns of calcined LATP powders derived from the sol-gel route on the left and enlarged sections on the right showing the second phases
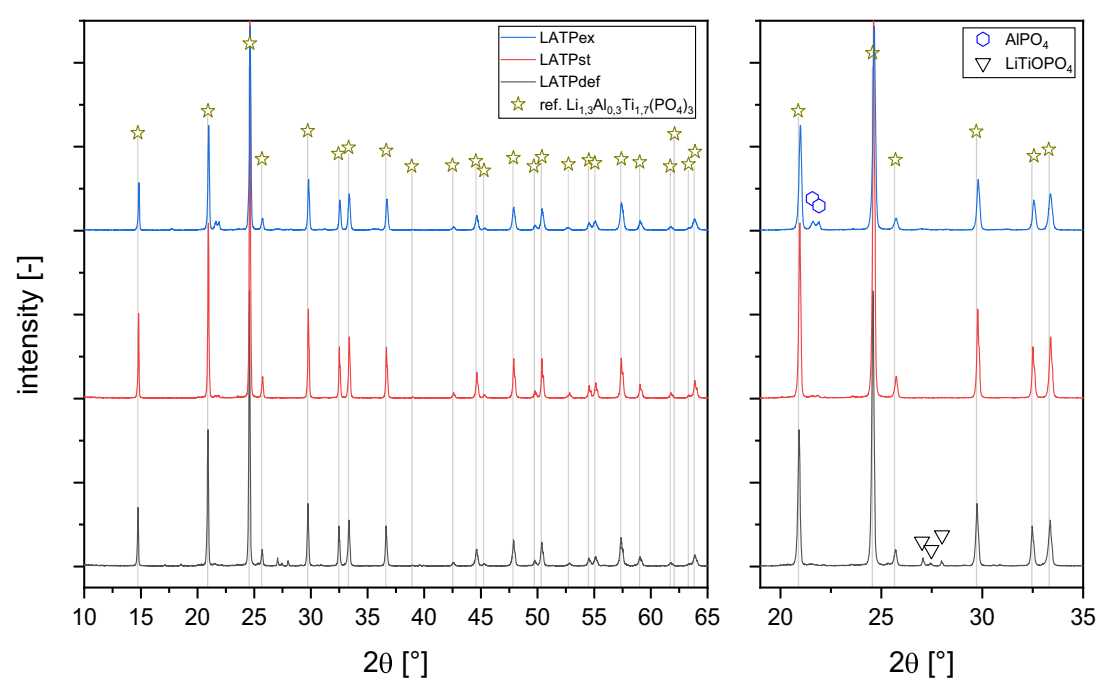
Table 1 Results of Rietveld refinement of diffraction patterns (Mo $\mathrm{K}_{\alpha 1}$ radiation) from calcined powders and sintered samples of LATPex, LATPst, and LATPdef

\begin{tabular}{lllll}
\hline Sample & Second phase $(w t \%)$ & Lattice parameter $(\AA)$ & Cell volume $\left(\AA^{3}\right)$ & Structural strain $\left(\mathrm{dD} / \mathrm{D} \times 10^{-4}\right)$ \\
\hline $\begin{array}{l}\text { LATPex } \\
\text { calcined powder }\end{array}$ & $4.7( \pm 0.4) \mathrm{AlPO}_{4}$ & $\mathrm{a}, \mathrm{b}=8.5115$ & 1308.2 & 16.6 \\
LATPex & & $\mathrm{c}=20.8507$ & $( \pm 0.1)$ & $( \pm 0.1)$ \\
$900{ }^{\circ} \mathrm{C}$ 480min & $4.14( \pm 0.4) \mathrm{AlPO}_{4}$ & $\mathrm{a}, \mathrm{b}=8.5078$ & $1306.3 \downarrow$ & $( \pm .0 \downarrow$ \\
LATPst & - & $\mathrm{c}=20.8388$ & $130.1)$ & 11.7 \\
calcined powder & & $\mathrm{a}, \mathrm{b}=8.5058$ & $( \pm 0.4)$ & $( \pm 0.1)$ \\
LATPst & - & $\mathrm{c}=20.8112$ & $1314.7 \uparrow$ & $( \pm 0.2)$ \\
$900{ }^{\circ} \mathrm{C}$ 30min & & $\mathrm{a}, \mathrm{b}=8.5176$ & $( \pm 0.8)$ & 17.8 \\
LATPdef & $5.6( \pm 0.4) \mathrm{LiTiOPO}_{4}$ & $\mathrm{c}=20.9248$ & 1303.3 & $( \pm 0.2)$ \\
calcined powder & & $\mathrm{a}, \mathrm{b}=8.5035$ & $( \pm 0.1)$ & $11.2 \downarrow$ \\
LATPdef & $3.5( \pm 0.5) \mathrm{LiTiOPO}_{4}$, & $\mathrm{c}=20.8119$ & $1287.0 \downarrow \downarrow$ & $( \pm 0.3)$ \\
$1000{ }^{\circ} \mathrm{C}$ & $1.8( \pm 0.4) \mathrm{TiO}_{2}$ & $\mathrm{a}, \mathrm{b}=8.4692$ & $( \pm 0.01)$ & \\
480 min & & $\mathrm{c}=20.7187$ & & \\
\hline
\end{tabular}

Arrows indicate the deviation of the sintered samples to the corresponding calcined powder

XRD investigations of selected sintered samples show the influence of the heat treatment on the crystal structure and the evolution of the secondary phases. The parameters extracted from Rietveld refinements are also listed in Table 1. The sample sintered from LATPst powder remains phase pure but shows more structural strain and an expansion of the unit cell predominantly along the c-axis. The sample derived from LATPex powder features a slight decline in the unit cell volume and a reduction of the structural strain. $\mathrm{AlPO}_{4}$ remains present as a second phase. The analysis of a sintered LATPdef sample shows less structural strain and a contraction of the unit cell mainly by shortening of the c-axis. There is less secondary phase $\mathrm{LiTiOPO}_{4}$ present compared to the calcined powder, but $\mathrm{TiO}_{2}$ is detectable in addition. The results are compatible with the $\mathrm{Li}_{2} \mathrm{O}-\mathrm{TiO}_{2}-\mathrm{P}_{2} \mathrm{O}_{5}$ phase diagram, given in Fig. 6, which shows that a phosphor deficient composition will be located in the marked compatibility triangle LiTiOPO $4-\mathrm{TiO}_{2}-\mathrm{LiTi}_{2}\left(\mathrm{PO}_{4}\right)_{3}$ as it is confirmed by XRD. It seems that $\mathrm{LiTiOPO}_{4}$ decomposes under formation of $\mathrm{TiO}_{2}$. Please note that the pseudo-ternary phase is only a guidance to understand the phase assemblage, but present compositions would require more details of the unknown pseudo- quaternary phase diagram $\mathrm{Li}_{2} \mathrm{O}-\mathrm{Al}_{2} \mathrm{O}_{3}-\mathrm{TiO}_{2}-\mathrm{P}_{2} \mathrm{O}_{5}$. The pseudo-ternary phase diagram also indicates tentatively the phase formation for LATPex: an Al-free composition would be located in the compatible triangle $\mathrm{Li}_{3} \mathrm{PO}_{4}-\mathrm{TiP}_{2} \mathrm{O}_{7^{-}}$ $\mathrm{LiTi}_{2}\left(\mathrm{PO}_{4}\right)_{3}$, but in the presence of aluminum, $\mathrm{AlPO}_{4}$ is mainly formed.

Thus, depending on the reactants' concentrations in the synthesis, significant differences in the phase assemblage and relative density are obtained in the considered sintering parameter range. In order to investigate these relationships in more detail, the microstructure of the samples was subsequently examined by SEM. For additional detailed insights, images with a higher magnification are provided in the Supporting Information (Figure S17-S19). Particularly interesting is the comparison of the microstructure for samples with a relative density $>90 \%$. The microstructural development of the LATPst samples sintered at $900{ }^{\circ} \mathrm{C}$ is shown in Fig. 7. After $10 \mathrm{~min}$, a homogenous and relatively dense microstructure was formed with small and uniform grains and very small and finely distributed pores. The homogeneity of the microstructure remains after sintering for $30 \mathrm{~min}$, but the individual grains start to grow slowly. The pores are slightly lager but of a substantially lower
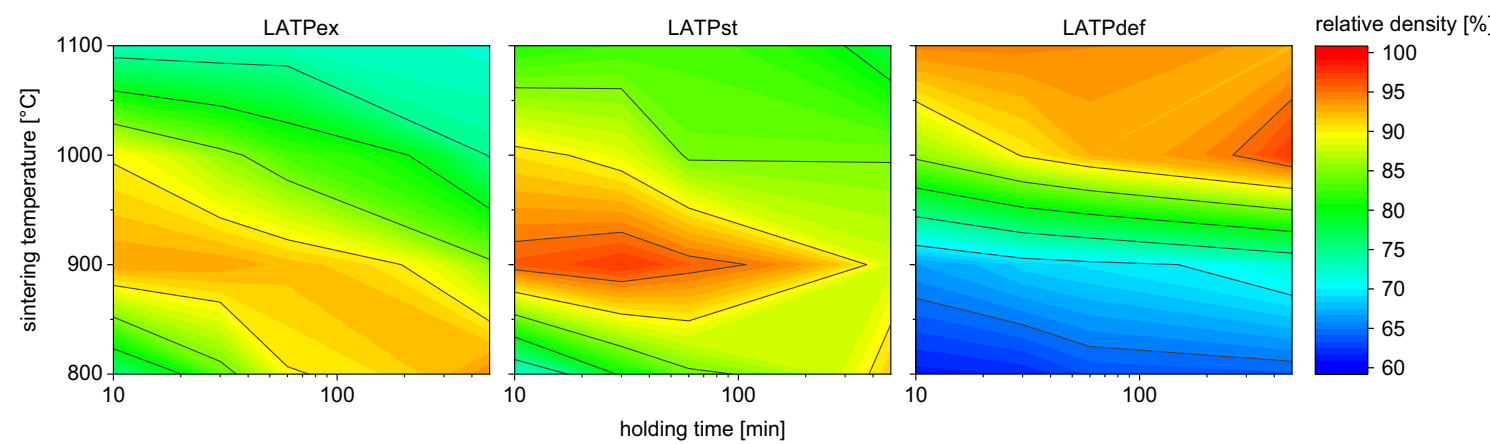

Fig. 5 Measured relative density of the LATP samples at different sintering temperatures and different holding times 


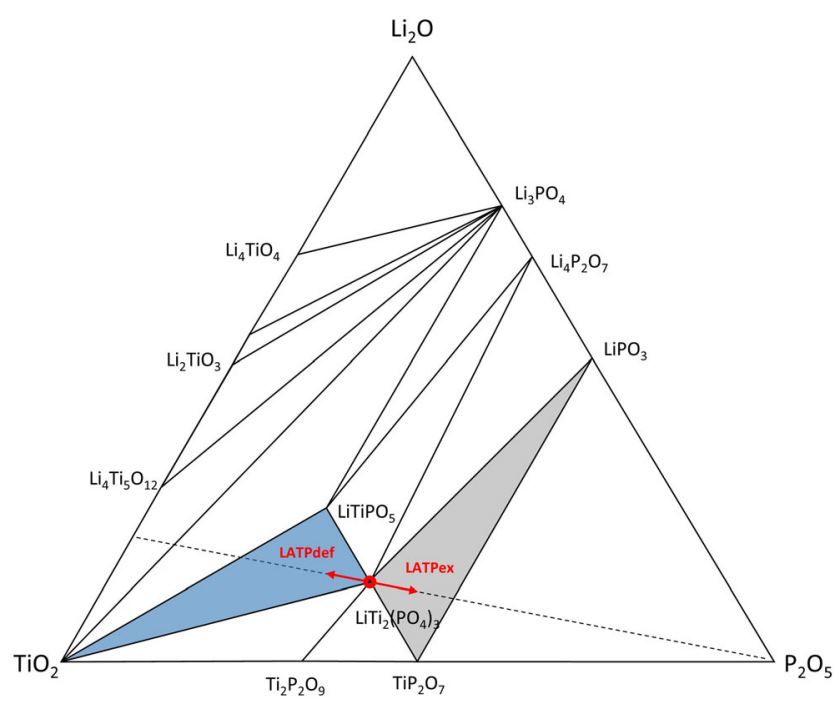

Fig. 6 Experimentally determined phase diagram by Robertson et al. [19] for the $\mathrm{Li}_{2} \mathrm{O}-\mathrm{TiO}_{2}-\mathrm{P}_{2} \mathrm{O}_{5}$ system. The red arrow indicates the deviation from the stoichiometric amount of phosphor for the $\mathrm{LiTi}_{2}\left(\mathrm{PO}_{4}\right)_{3}$ phase

number. After sintering for $1 \mathrm{~h}$, it became apparent that several grains grow abnormal as indicated by very pronounced intragranular porosity; this trend continues for even longer sintering times. At $480 \mathrm{~min}$, the formation of microcracks can be seen in large grains. This observation agrees with previous works. These studies attribute the formation of microcracks to the high thermal expansion anisotropy between the a and c lattice parameters, which is known for NASICON-type materials [20-22]. The anisotropic elongation of the c-axis and the buildup of structural strain was also indicated in the previously described XRD analysis of sintered LATPst samples. That behavior also explains why the relative density decreases again with longer holding times.

The microstructural development of the LATPex samples also sintered at $900{ }^{\circ} \mathrm{C}$ is shown in Fig. 8. Here, homogeneously small grains can be observed for a holding time of $10 \mathrm{~min}$. Towards longer holding times, individual grains start to grow just as seen for LATPst. One big difference is that the microstructures show a very uneven surface. During the preparation process, pieces have repeatedly broken out of the sample, and it was not possible to achieve a polished surface. For the sample sintered for $480 \mathrm{~min}$, a lot of gaps can be seen where probably whole grains broke out of the surface during the preparation. That indicates a weak mechanical cohesion at the grain boundary. A possible explanation could be a weakening accumulation of the second phase $\mathrm{AlPO}_{4}$ at the grain boundary.

A very different picture emerges when looking at the microstructures of the LATPdef samples, sintered at $900{ }^{\circ} \mathrm{C}$. At this temperature, there is almost no densification and the individual starting particles can still be seen as depicted in Figure S20. Therefore, the much more informative microstructures of samples sintered at $1000{ }^{\circ} \mathrm{C}$, depicted in Fig. 9, are discussed here. Although the sintering temperature is 100 ${ }^{\circ} \mathrm{C}$ higher, almost no densification is observed for short holding times compared to LATPst. By increasing the holding time to $480 \mathrm{~min}$, a homogeneous microstructure is achieved. The grain growth is moderate, and consequently, the associated microcracks do not occur in this case. Grain growth seems to be suppressed by second-phase particles, which are visible as homogeneously distributed bright dots in all micrographs of Fig. 9. The assumption that it corresponds to the second phase $\mathrm{TiO}_{2}$ was confirmed by EDX analysis. The interaction between second-phase particles and migrating grain boundaries is well-known for ceramic materials. It is denoted as Zener-type mechanism and reduces grain growth [23].

The electrochemical analysis shows how the differences in sintering behavior and microstructure evolution of the LATP samples affect their ionic conductivity. As explained in the experimental section, the values for the total ionic
Fig. 7 Microstructure of LATPst samples that were sintered at 900

${ }^{\circ} \mathrm{C}$ with holding times from

10 min up to $480 \mathrm{~min}$
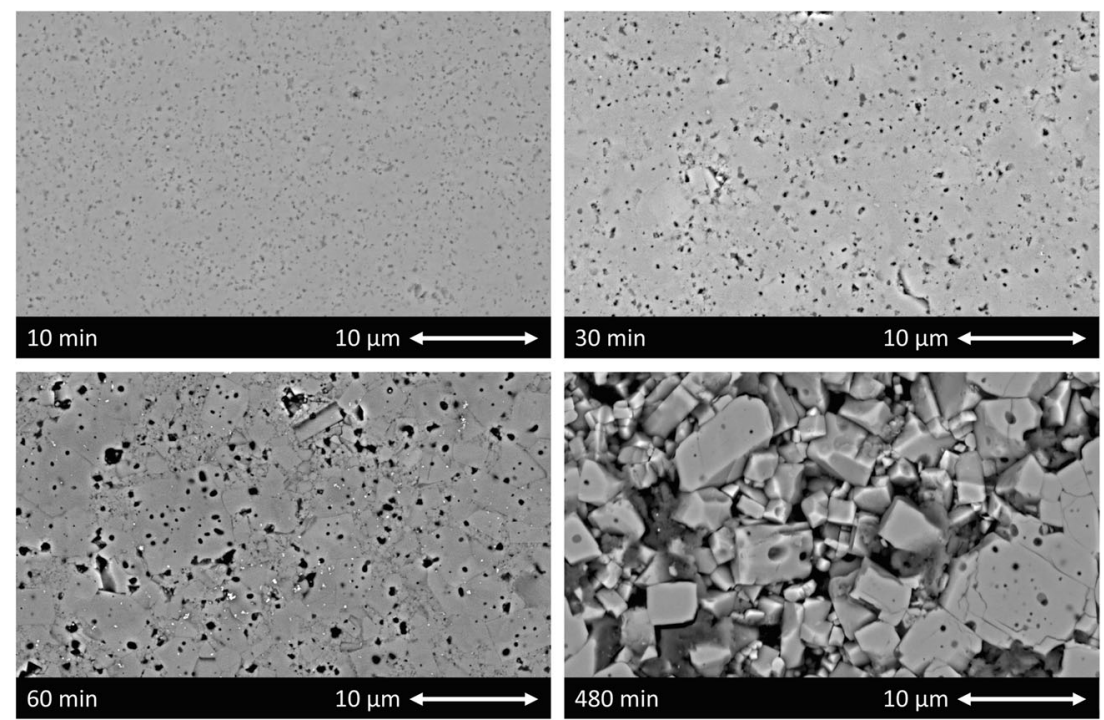
Fig. 8 Microstructure of LATPex samples that were sintered at 900

${ }^{\circ} \mathrm{C}$ with holding times from

$10 \mathrm{~min}$ up to $480 \mathrm{~min}$
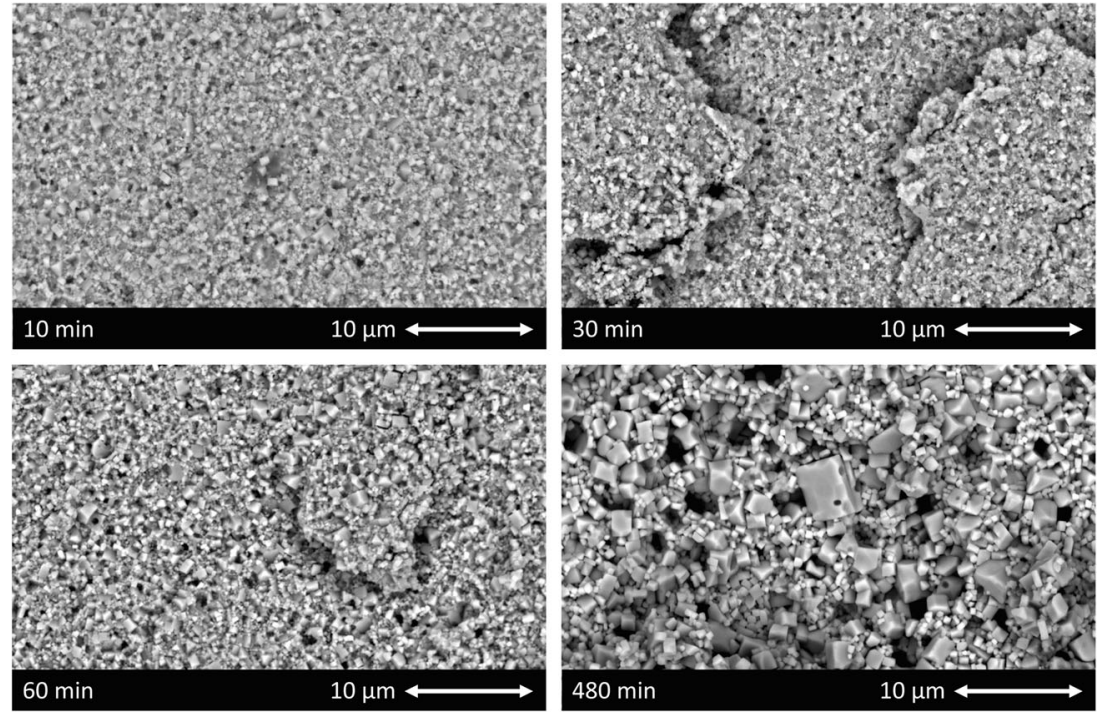

conductivity were derived from impedance measurements performed in potentiostatic mode. The conductivity map is shown in Fig. 10, plotted analogously to the density over temperature and holding time. The exact values of ionic conductivity for the different sintering temperatures and holding times are listed in Table 5-7. For samples made from LATPst powder, the highest ionic conductivity values were obtained by sintering at $900{ }^{\circ} \mathrm{C}$, which coincides very well with high density values reached for this temperature. A maximum of $1.02 \cdot 10^{-3} \mathrm{~s} / \mathrm{cm}$ is obtained after 30 -min sintering, where a homogenous and dense microstructure can be found. We attribute the increase in ionic conductivity from 10 to $30 \mathrm{~min}$ of sintering time to the change in the pore distribution and to the slightly larger grains. The lower ionic conductivity for sintering times of $60 \mathrm{~min}$ and longer can be attributed to an increasing microstructural inhomogeneity. Especially the formation of microcracks in abnormally grown grains due to the high thermal expansion anisotropy causes a decrease in ionic conductivity. First indications of this effect could already be seen in the results for the Rietveld refinement of the LATPst sample sintered at $900{ }^{\circ} \mathrm{C}$ for $30 \mathrm{~min}$. The sintered samples from LATPex powder generally show a lower ionic conductivity with maximum values around $1 \cdot 10^{-4} \mathrm{~s} / \mathrm{cm}$. The factors contributing to that are probably the poor densification behavior and the weak grain boundaries caused by the second phase $\mathrm{AlPO}_{4}$, which is still detectable in the XRD pattern after sintering. It is assumed that $\mathrm{AlPO}_{4}$ accumulates at the grain boundaries and thereby weakens them. As with the LATPst samples, the LATPdef samples also show good ionic conductivity for the densest samples. The maximum value of 1.09 . $10^{-3} \mathrm{~s} / \mathrm{cm}$ is measured for the sample sintered at $1000^{\circ} \mathrm{C}$ for $480 \mathrm{~min}$. Microcrack formation that causes poor conductivity in LATPst samples at this long holding time and high temperature does not seem to occur here, probably because abnormal
Fig. 9 Microstructure of LATPdef samples that were sintered at $1000{ }^{\circ} \mathrm{C}$ with holding times from $10 \mathrm{~min}$ up to $480 \mathrm{~min}$
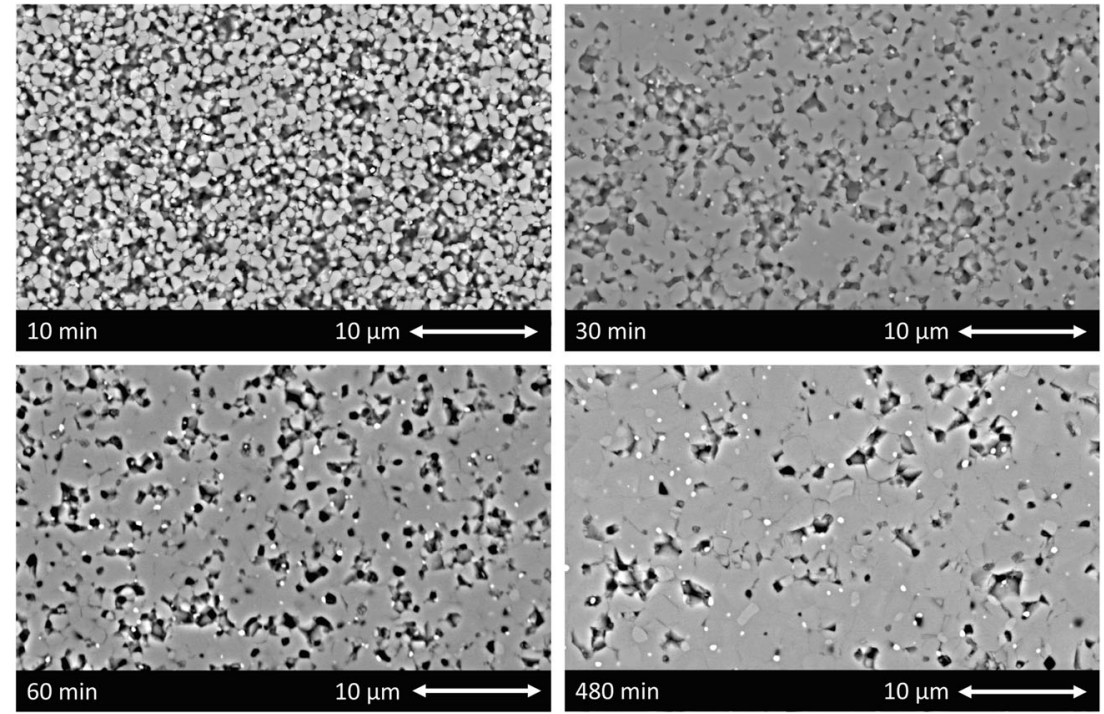

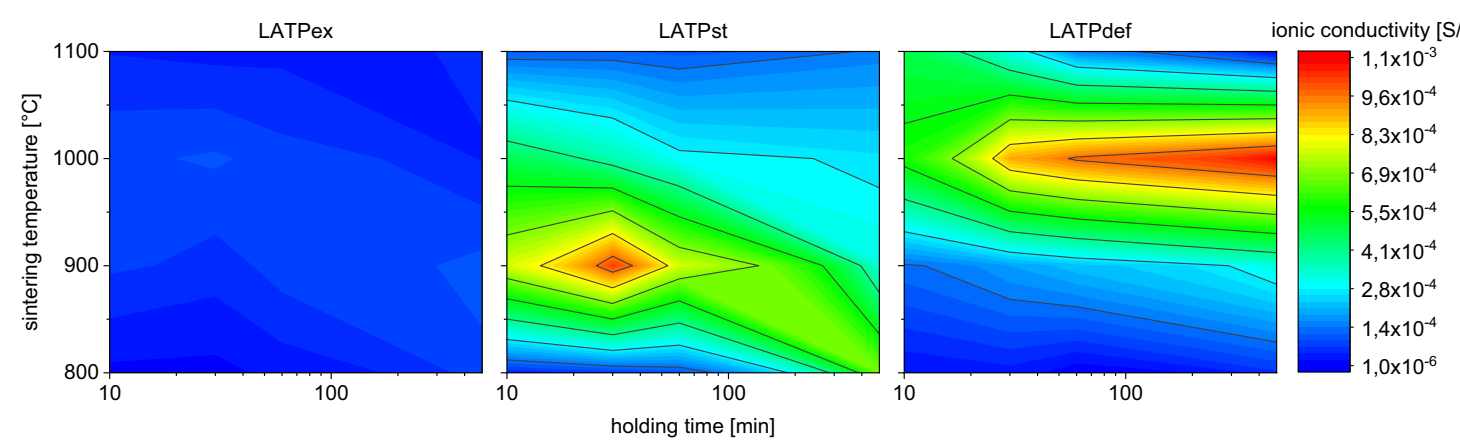

Fig. 10 Ionic conductivity of the LATP samples at different sintering temperatures and different holding times

grain growth is prevented by the presence of the second phase $\mathrm{TiO}_{2}$. Although the density values of the samples sintered at $1100{ }^{\circ} \mathrm{C}$ are also high, the ionic conductivity is significantly lower. In the SEM images, it could be seen that at $1100^{\circ} \mathrm{C}$, the second phase could no longer prevent the grain growth and became overgrown. As a result, microcracks form and the ionic conductivity drops significantly.

\section{Summary and conclusions}

Our study shows that several process parameters for upscaling of a sol-gel synthesis of LATP have to be decisively controlled. It can be seen that a stoichiometric sol-gel synthesis gives the opportunity to obtain high ionic conductivities, in the order of $1 \cdot 10^{-3} \mathrm{~s} / \mathrm{cm}$, with a low energy input of only $900{ }^{\circ} \mathrm{C}$ for sintering and holding times of maximum $30 \mathrm{~min}$. However, locally occurring fluctuations in the concentration of $\mathrm{H}_{3} \mathrm{PO}_{4}$ could possibly have greater impact. If an excess of $\mathrm{H}_{3} \mathrm{PO}_{4}$ occurs in the process, it will lead to the formation of the second phase $\mathrm{AlPO}_{4}$, which may then prevent the formation of suitable conduction pathways for good ionic conductivity. A deficiency of phosphoric acid in the synthesis leads to the formation of $\mathrm{LiTiOPO}_{4}$, which seems to be the reason for a hindered densification, but also prevents abnormal grain growth for sintering temperatures up to $1000{ }^{\circ} \mathrm{C}$. Thereby, comparably high ionic conductivities can be obtained, but the sintering parameters have to be adjusted to a higher temperature and longer holding time.

Supplementary Information The online version contains supplementary material available at https://doi.org/10.1007/s11581-021-03961-x.

Acknowledgement The authors gratefully acknowledge the financial support provided by the Bundesministerium für Bildung und Forschung (BMBF contract numbers 03XP0173 and 03XP0176A).
Funding Open Access funding enabled and organized by Projekt DEAL.

Open Access This article is licensed under a Creative Commons Attribution 4.0 International License, which permits use, sharing, adaptation, distribution and reproduction in any medium or format, as long as you give appropriate credit to the original author(s) and the source, provide a link to the Creative Commons licence, and indicate if changes were made. The images or other third party material in this article are included in the article's Creative Commons licence, unless indicated otherwise in a credit line to the material. If material is not included in the article's Creative Commons licence and your intended use is not permitted by statutory regulation or exceeds the permitted use, you will need to obtain permission directly from the copyright holder. To view a copy of this licence, visit http://creativecommons.org/licenses/by/4.0/.

\section{References}

1. Zhu J, Zhao J, Xiang Y et al (2020) Chemomechanical failure mechanism study in NASICON-type $\mathrm{Li}_{1.3} \mathrm{Al}_{0.3} \mathrm{Ti}_{1.7}\left(\mathrm{PO}_{4}\right)_{3}$ solidstate lithium batteries. Chem Mater 32:4998-5008. https://doi.org/ 10.1021/acs.chemmater.9b05295

2. Khokhar WA, Zhao N, Huang W et al (2020) Different behaviors of metal penetration in na and li solid electrolytes. ACS Appl Mater Interfaces. https://doi.org/10.1021/acsami.0c15230

3. Liang JY, Zeng XX, Zhang XD et al (2019) Engineering janus interfaces of ceramic electrolyte via distinct functional polymers for stable high-voltage Li-metal batteries. J Am Chem Soc 141: 9165-9169. https://doi.org/10.1021/jacs.9b03517

4. Wang S, Li S, Wei B, Lu X (2020) Interfacial engineering at cathode/LATP interface for high-performance solid-state batteries. J Electrochem Soc 167:100528. https://doi.org/10.1149/19457111/ab9a00

5. Aono H, Sugimoto E, Sadaoka Y et al (1990) Ionic conductivity of solid electrolytes based on lithium titanium phosphate. J Electrochem Soc 137:1023-1027. https://doi.org/10.1149/1. 2086597

6. Alamo J (1993) Chemistry and properties of solids with the [NZP] skeleton. Solid State Ionics 63-65:547-561. https://doi.org/10. 1016/0167-2738(93)90158-Y

7. Arbi K, Hoelzel M, Kuhn A et al (2013) Structural factors that enhance lithium mobility in fast-ion $\mathrm{Li}_{1+\mathrm{x}} \mathrm{Ti}_{2-\mathrm{x}} \mathrm{Al}_{\mathrm{x}}\left(\mathrm{PO}_{4}\right)_{3}(0 \leq \mathrm{x} \leq$ $0.4)$ conductors investigated by neutron diffraction in the temperature range 100-500 K. Inorg Chem 52:9290-9296. https://doi.org/ $10.1021 / \mathrm{ic} 400577 \mathrm{v}$

8. Lang B, Ziebarth B, Elsässer C (2015) Lithium ion conduction in $\mathrm{LiTi}_{2}\left(\mathrm{PO}_{4}\right)_{3}$ and related compounds based on the NASICON structure: a first-principles study. Chem Mater 27:5040-5048. https:// doi.org/10.1021/acs.chemmater.5b01582 
9. Ma Q, Xu Q, Tsai CL et al (2016) A novel sol-gel method for largescale production of nanopowders: preparation of $\mathrm{Li}_{1.5} \mathrm{Al}_{0.5} \mathrm{Ti}_{1.5}\left(\mathrm{PO}_{4}\right)_{3}$ as an example. J Am Ceram Soc 99:410414. https://doi.org/10.1111/jace.13997

10. Pérez-Estébanez M, Isasi-Marín J, Többens DM et al (2014) A systematic study of Nasicon-type $\mathrm{Li}_{1+\mathrm{x}} \mathrm{M}_{\mathrm{x}} \mathrm{Ti}_{2-\mathrm{x}}\left(\mathrm{PO}_{4}\right)_{3}$ (M: Cr, Al, $\mathrm{Fe})$ by neutron diffraction and impedance spectroscopy. Solid State Ionics 266:1-8. https://doi.org/10.1016/j.ssi.2014.07.018

11. Narváez-Semanate JL, Rodrigues ACM (2010) Microstructure and ionic conductivity of $\mathrm{Li}_{1+\mathrm{x}} \mathrm{Al}_{\mathrm{x}} \mathrm{Ti}_{2-\mathrm{x}}\left(\mathrm{PO}_{4}\right)_{3}$ NASICON glass-ceramics. Solid State Ionics 181:1197-1204. https://doi.org/10. 1016/j.ssi.2010.05.010

12. Bucharsky EC, Schell KG, Hintennach A, Hoffmann MJ (2015) Preparation and characterization of sol-gel derived high lithium ion conductive NZP-type ceramics $\mathrm{Li}_{1+\mathrm{x}} \mathrm{Al}_{\mathrm{x}} \mathrm{Ti}_{2-\mathrm{x}}\left(\mathrm{PO}_{4}\right)_{3}$. Solid State Ionics 274:77-82. https://doi.org/10.1016/j.ssi.2015.03.009

13. Hupfer T (2018) Herstellung von LATP für den Einsatz als Festkörperelektrolyt und dessen Eigenschaften. KIT Scientific Publishing, Karlsruhe

14. Arbi K, Mandal S, Rojo JM, Sanz J (2002) Dependence of ionic conductivity on composition of fast ionic conductors $\mathrm{Li}_{1+\mathrm{x}} \mathrm{Ti}_{2-}$ ${ }_{x} \mathrm{Al}_{\mathrm{x}}\left(\mathrm{PO}_{4}\right)_{3}, 0 \leq \mathrm{x} \leq 0.7$. A parallel NMR and electric impedance study. Chem Mater 14:1091-1097. https://doi.org/10.1021/ $\mathrm{cm} 010528 \mathrm{i}$

15. Bucharsky EC, Schell KG, Hoffmann MJ (2015) Verfahren zur Herstellung von $\mathrm{Li}_{1+\mathrm{x}} \mathrm{Ti}_{2-\mathrm{x}} \mathrm{Al}_{\mathrm{x}}\left(\mathrm{PO}_{4}\right)_{3}$ und dessen Verwendung als Festkörperelektrolyt. EP 2838836 B1 Europäisches Patentamt, Karlsruhe
16. Levy D, Zayat M (2015) The Sol-Gel Handbook_ Synthesis, Characterization and Applications, 3-Volume. Set-Wiley-VCH

17. Hupfer T, Bucharsky EC, Schell KG, Hoffmann MJ (2017) Influence of the secondary phase $\mathrm{LiTiOPO}_{4}$ on the properties of $\mathrm{Li}_{1+\mathrm{x}} \mathrm{Al}_{\mathrm{x}} \mathrm{Ti}_{2-\mathrm{x}}\left(\mathrm{PO}_{4}\right)_{3}(\mathrm{x}=0 ; 0.3)$. Solid State Ionics 302:49-53. https://doi.org/10.1016/j.ssi.2016.10.008

18. Rodríguez-Carvajal J (1993) Recent advances in magnetic structure determination by neutron powder diffraction. Phys B Phys Condens Matter 192:55-69. https://doi.org/10.1016/0921-4526(93)90108-I

19. Robertson A, Fletcher JG, Skakle JMS, West AR (1994) Synthesis of $\mathrm{LiTiPO}_{5}$ and $\mathrm{LiTiAsO}_{5}$ with the $\alpha-\mathrm{Fe}_{2} \mathrm{PO}_{5}$ structure. J Solid State Chem 109:53-59. https://doi.org/10.1006/jssc.1994.1070

20. Hupfer T, Bucharsky EC, Schell KG et al (2016) Evolution of microstructure and its relation to ionic conductivity in $\mathrm{Li}_{1+\mathrm{x}} \mathrm{Al}_{\mathrm{x}} \mathrm{Ti}_{2}$ ${ }_{-\mathrm{x}}\left(\mathrm{PO}_{4}\right)_{3}$. Solid State Ionics 288:235-239. https://doi.org/10.1016/j. ssi.2016.01.036

21. Jackman SD, Cutler RA (2012) Effect of microcracking on ionic conductivity in LATP. J Power Sources 218:65-72. https://doi.org/ 10.1016/j.jpowsour.2012.06.081

22. Waetzig K, Rost A, Langklotz U et al (2016) An explanation of the microcrack formation in $\mathrm{Li}_{1.3} \mathrm{Al}_{0.3} \mathrm{Ti}_{1.7}\left(\mathrm{PO}_{4}\right)_{3}$ ceramics. $\mathrm{J}$ Eur Ceram Soc 36:1995-2001. https://doi.org/10.1016/j.jeurceramsoc. 2016.02.042

23. Rahaman MN (2007) Sintering of ceramics. CRC Press, Boca Raton

Publisher's note Springer Nature remains neutral with regard to jurisdictional claims in published maps and institutional affiliations. 